\title{
Implantable sensor technology: measuring bone and joint biomechanics of daily life in vivo
}

\author{
Darryl D D'Lima'*, Benjamin J Fregly ${ }^{2}$ and Clifford W Colwell Jr'
}

Abstract
Stresses and strains are major factors influencing
growth, remodeling and repair of musculoskeletal
tissues. Therefore, knowledge of forces and
deformation within bones and joints is critical to
gain insight into the complex behavior of these
tissues during development, aging, and response to
injury and disease. Sensors have been used in vivo
to measure strains in bone, intraarticular cartilage
contact pressures, and forces in the spine, shoulder,
hip, and knee. Implantable sensors have a high
impact on several clinical applications, including
fracture fixation, spine fixation, and joint arthroplasty.
This review summarizes the developments in strain-
measurement-based implantable sensor technology
for musculoskeletal research.

\section{Introduction}

Biomechanics plays a major role in orthopedic injury, disease, and treatment. The form and function of the musculoskeletal system is primarily mechanical in nature, supporting and protecting the rest of the body, and facilitating movement and locomotion. This system is made possible through the intricate interactions between bone, cartilage, ligaments, muscles and tendons. Stresses and strains are major factors influencing growth, remodeling and repair of these tissues. Therefore, knowledge of forces and deformation within bones and joints is critical to gain insight into the complex behavior of these tissues during development, growth, maturation, and aging; as well as the responses to injury, disease, and healing.

One of the most commonly used types of musculoskeletal sensor is one that measures strain [1-5]. By

\footnotetext{
*Correspondence: Dlima.Darryl@scrippshealth.org

'Scripps Health, Shiley Center for Orthopaedic Research and Education at Scripps Clinic, 11025 North Torrey Pines Road, Suite 200, La Jolla, CA 92037-1030, USA
} Full list of author information is available at the end of the article monitoring strain one can determine local tissue deformations and stresses in bone and cartilage. Tissue strains have been measured in vivo in animals with implanted telemetry (wireless) systems or in humans with temporary (precutaneously wired) strain gages [1-3,6]. Orthopedic implants, such as joint arthroplasty components and spinal fixation devices, offer a convenient mechanism for sensor placement as well as to accommodate electronic components such as microprocessors, radiotransmitters, and power sources [7-11]. By calibrating strain against applied force, strain sensors in implants have been used to measure net joint loads. Sensors were initially wired and accessible only through percutaneous connections, which only permitted short-term data collection [1,12]. Radiotransmitters made it possible to develop fully implantable wireless systems (telemetry) that permitted longer-term data monitoring $[9,13]$.

Implantable sensors have a high impact on several musculoskeletal clinical applications, including fracture fixation, spine fixation, and joint arthroplasty. Examples include monitoring the strength and progression of fracture healing and spine fusion; identifying risk for implant fatigue, migration and loosening; and monitoring of wear and damage in bearing surfaces. This review summarizes the developments in strain measurementbased implantable sensor technology for musculoskeletal research in general, with a special emphasis on the knee joint.

\section{In vivo strain measurement in bone}

Lanyon and colleagues measured bone strains in vivo as early as 1975 [1]. Strain magnitudes and orientation of principal strains varied widely based on activity as well as within each activity cycle. Later measurements in subjects performing activities at a higher level revealed higher than expected strain rates (reaching 0.05/second), although peak strain magnitudes remained below 2,000 microstrain and below those measured in animals [2]. The invasive nature of these strain gage measurements only permitted temporary implantation and sample sizes were limited to measurements in one or two subjects.

One challenge for long-term measurement of direct tissue strains in vivo is the debonding of standard strain 
sensors from the underlying tissue within a few weeks. On the other hand, sensors attached to porous tissue ingrowth surfaces can lose their original accuracy as the tissue ingrowth progresses [3]. One approach to overcome this challenge is coating sensors to enhance direct biological bonding to bone.

This approach of coating strain sensors was used for measurement of strains in the lamina of lower thoracic vertebrae and the rod of segmental fixation for scoliosis surgery (monitored postoperatively in one subject) [11]. These measurements provided a useful record of how the process of integration of calcium phosphate ceramiccoated strain gages to bone and progression of spinal fusion affected early postoperative strains. While these results appear to be specific to the individual tested, this approach may be valuable as a more sensitive, quantitative, and biomechanically relevant method of monitoring fusion than serial radiographs [14].

\section{In vivo strain measurement in fracture fixation}

Instrumenting external fixation systems with strain gages provides a convenient, although temporary, method of measuring displacement and stiffness of the fracture site. Increasing stiffness during fracture healing allows quantitative monitoring of the process. A threshold for bending stiffness of $15 \mathrm{~N}$-m/degree for tibial fractures and $20 \mathrm{~N}-\mathrm{m} /$ degree for femoral fractures has been established as a marker of acceptable healing and to permit removal of the fixator [15-17]. In the early 1970s, Burny and coworkers used percutaneous leads to measure loads during fracture healing by instrumenting fracture plates with strain gages [18]. Brown and coworkers used battery powered telemetry-based systems to monitor forces in proximal femoral nail plate fixation systems [9]. Peak bending moments of $20 \mathrm{~N}$-m about the anteroposterior axis were reported for walking during the early postoperative period (within 4 weeks of surgery) before fracture healing. Of note were the relatively higher than expected axial moments (up to $12 \mathrm{~N}-\mathrm{m}$ ). Since fracture healing significantly reduced the forces and moments on the nail-plate, long-term monitoring of hip forces was not relevant. A femoral intramedullary nail instrumented with sensors and a telemetry system were used to monitor femoral forces during the fracture healing process and reported a $50 \%$ decrease in loading over the first 6 months after fixation [19].

\section{In vivo pressures in cartilage}

Metal-on-cartilage contact pressures were measured using a hemi-arthroplasty femoral component, with pressure sensors on the articular surface of the head $[10,20]$. Peak pressures were much higher (up to $18 \mathrm{MPa}$ ) than those measured previously in vitro and were attributed to dynamic events and muscle co-contraction.
Percutaneous pressure sensors have been inserted during arthroscopy to temporarily monitor medial compartmental cartilage-on-cartilage pressures [21]. However, direct measurement of cartilage strains in vivo with more permanent implants has, to date, been possible only in animals. These in vivo measurements of cartilage stresses in canines revealed subtle alterations in force that would have been difficult to detect with external (non-implanted) measurements $[6,22,23]$. For example, changes in joint loading induced by anterior cruciate ligament transection could be quantified. The individual contributions of pain and instability were also independently identified by measuring the change in loading response to antiinflammatory treatment, which supports the translational relevance of such preclinical studies.

\section{Implantable sensors in the hip joint}

Forces acting on implanted femoral components were measured in vivo by Rydell as early as 1966 [12]. While the implants were permanent, the precutaneously wired connections were temporary and were designed to be removed after early postoperative data collection. In the mid to late 70s, passive (powered by inductive coupling) telemetry (wireless) systems were used to measure metalon-cartilage pressures in a hemiarthroplasty [24,25]. Battery-powered telemetry has also been used to measure forces in a total hip arthroplasty femoral component, which peaked at nearly 2.5 times body weight (xBW) during walking on the 12th postoperative day [13].

Sensors that measure hip pressures or forces have been implanted in the hip joint by several research groups, making in vivo hip forces one of the most widely reported joint forces [10,26-28]. The underlying principles of strain gage measurement of forces and inductive electromagnetic powering of the telemetry system have remained the same. However, three generations of hip components have been developed and implanted, resulting in the current capability of measuring three components of force and three moments acting across the femoroacetabular joint [29].

During walking, hip joint forces peaked between 2.2 to $3.3 \mathrm{xBW}$ [27]. Hip forces were sensitive to the velocity of walking and peaked at $5 \mathrm{xBW}$ during jogging, but were much less sensitive to the type of footwear or to the type of walking surface $[27,30]$. The importance of involuntary muscle contraction was emphasized when forces approaching $9 \mathrm{xBW}$ were recorded during an episode of stumbling [31]. The direction of the peak force vector relative to the acetabulum was found to be consistent between subjects supporting the conventional wisdom of adaption and development of the musculoskeletal system in response to external forces [32]. These measurements directly support the need to more precisely reconstruct the center of the hip joint after arthroplasty and to avoid 
deviation from normal femoral anteversion in order to reduce the risk of abnormal forces on the implanted components. Experimental results from implanted hip sensors have been widely cited and used for validation of, and as data input into, several computer models and have advanced the in vitro and preclinical assessment of hip implants [33-36].

\section{Implantable sensors in the spine}

Around the same time as Rydell's attempt to measure hip forces, Waugh used Harrington rods instrumented with strain gages for spine fixation to measure forces in vivo [37]. As with Rydell's femoral component, the strain gages on the Harrington rods connected via percutaneous wires allowed measurement for only one day. By the early 1970s, telemetry systems were temporarily implanted to measure early postoperative forces in the spine $[38,39]$. Since then forces in the spine have been measured over longer durations using instrumented spine fixation devices [40], strain gages on the lamina [11], and instrumented vertebral body replacement [41].

High vertebral body loads have been measured even during the first postoperative month after implantation with a vertebral body replacement. These forces ranged from $100 \mathrm{~N}$ when lying down, to over $700 \mathrm{~N}$ when carrying weights or exercising against resistance [41]. Vertebral laminar strains peaked at nearly 2,000 microstrain while climbing stairs: an unexpected finding suggesting that trunk flexion to reduce knee moments may place high strains on posterior elements of the spine [11]. Up until these instrumented implants made in vivo measurements possible, laboratory experiments were limited to cadaver experiments. In vivo, muscular effort was a major factor influencing the loads on the implant. However, the difficulty inherent in accurately simulating the effect of muscle forces explains the significant differences found between cadaver measurements and in vivo measurements [42].

Nachemson measured intradiscal pressures for the first time in vivo using an external pressure transducer connected to a temporary intradiscal needle [43]. Since then several reports of in vivo disk pressures using similar percutaneous techniques have been made, but longerterm monitoring of intervertebral body forces using fully implantable sensors has not been successfully accomplished in humans [44-46]. In baboons, even sitting with the spine flexed generated forces exceeding $4 \mathrm{xBW}$, which underscores the high magnitude of forces generated $[47,48]$. In humans too, sitting generated higher vertebral body forces than standing [49]. However, given the sensitivity of measured loads to the location of sensors in the spine, it appears likely that intervertebral forces or intradiscal forces may be different from loads measured in the posterior fixation or vertebral body.
In addition to the experimental observations, such as the effect of chair design on spinal forces [50], or changes in spinal fixator forces after a staged anterior interbody fusion [51], these data have been used to validate computational models [52], as well as to inform on developing more realistic in vitro models for spine testing [53].

\section{Implantable sensors in the shoulder joint}

The shoulder is one of the most complex of the major joints in the human body. The hip resembles a ball-andsocket joint; therefore, the stability is primarily governed by the bony anatomy. The shoulder, on the other hand, has an extensive range of motion and is stabilized primarily by muscles during most activities. Forces in and around the shoulder are directly related to many common shoulder disorders such as instability, tendinitis, rotator cuff tears, and arthritis: involving repetitive activities of daily living or athletic actions such as throwing. Shoulder arthroplasty therefore provides a convenient opportunity to implant sensors and telemetry systems in the shoulder to monitor forces during complex activities.

Forces in the shoulder were first measured in vivo using a shoulder arthroplasty humeral stem instrumented with a six-sensor, multichannel telemetry system [8]. Comparing across activities of daily living, the highest joint forces were recorded while steering a car with one hand, setting down $1.5 \mathrm{~kg}$ on a table, and lifting a $2 \mathrm{~kg}$ weight to a high shelf (all over 100\% bodyweight) [54]. Despite the classification of the shoulder as a non-weight bearing joint, forces in the shoulder peaked over $2.0 \mathrm{xBW}$ during forward flexion while holding a $2 \mathrm{~kg}$ weight [5]. For comparison, walking generates similar peak forces in the hip [27] and knee (Table 1). Activities requiring a high degree of control increased joint forces presumably due to increased muscular co-contraction. An unanticipated experimental finding was the increase in glenohumeral contact forces when the arm was raised above the shoulder [5]. Before in vivo experimental forces were available, most computational models that use muscle forces to balance the external adduction moments were unable to predict this increase. The speed of movement did have an effect on the magnitude of motion; however, contrary to expectations, faster movements decreased peak forces [5]. These results underscore the need for more accurate predictions of shoulder forces and highlight an inherent weakness of common approaches to musculoskeletal modeling, which makes it difficult to predict muscle agonistic and antagonistic co-contraction with a high degree of accuracy. Additionally, most computational models of the shoulder ignore articular friction, assuming it to be negligible, but the magnitude of moments recorded in the head of the humerus indicates that friction is likely to be an order of magnitude 
Table 1. Peak tibial forces during activities of daily living

\begin{tabular}{|c|c|c|}
\hline Activity & Peak tibial forces (xBW) & Notes \\
\hline Walking $[4,7,70,71,76]$ & $2.5-2.8$ & Laboratory floor \\
\hline Stair ascent $[4,76]$ & $2.9-3.2$ & $N=9$ \\
\hline Stair descent $[4,76]$ & $3.2-3.5$ & $N=9$ \\
\hline Treadmill walking [71] & $2.1 \pm 0.2$ & 1 to 3 miles per hour $(N=4)$ \\
\hline Power walking [71] & $2.8 \pm 0.4$ & 4 miles per hour on treadmill $(\mathrm{N}=4)$ \\
\hline Jogging [68] & $3.1-3.6$ & Tumor replacement prosthesis $(\mathrm{N}=1)$ \\
\hline Jogging [71] & $4.2 \pm 0.2$ & 5 miles per hour on treadmill $(\mathrm{N}=4)$ \\
\hline Stationary bicycling [71] & $1.0-1.5$ & Level 1-5; 60-90 rpm ( $\mathrm{N}=4)$ \\
\hline Golf (lead knee) [71] & $4.4 \pm 0.1$ & Left knee in a right handed golfer $(\mathrm{N}=4)$ \\
\hline Golf (trailing knee) [71] & $3.0 \pm 0.2$ & $N=4$ \\
\hline Tennis serve [71] & $4.2 \pm 0.1$ & $N=4$ \\
\hline Tennis forehand [71] & $4.3 \pm 0.4$ & $N=4$ \\
\hline Tennis backhand [71] & $3.5 \pm 0.6$ & $N=4$ \\
\hline StairMaster Level 1 [71] & $2.4 \pm 0.1$ & $N=4$ \\
\hline StairMaster Level 3 [71] & $3.3 \pm 0.3$ & $N=4$ \\
\hline Elliptical level 1 [71] & $2.3 \pm 0.2$ & $N=4$ \\
\hline Elliptical level 11 [71] & $2.2 \pm 0.3$ & $N=4$ \\
\hline Leg press [71] & $2.8 \pm 0.1$ & Foot reaction force $=1 \times B W(N=4)$ \\
\hline Knee extension [71] & $1.5 \pm 0.0$ & Resistance $=0.2 \times B W(N=4)$ \\
\hline Rowing machine [71] & $0.9 \pm 0.1$ & $N=4$ \\
\hline
\end{tabular}

XBW, times body weight. Adapted from [81].

greater (coefficient of friction 0.1 to 0.2 ) than estimated (0.01), and more important than previously thought [5].

\section{Implantable sensors in the knee joint}

The knee joint is a critical load-bearing joint that is often affected by injury and disease. Osteoarthritis, one of the most common forms of arthritis, has a strong biomechanical component. Forces and moments about the knee joint have been correlated with the severity and progression of osteoarthritis [55-67]. Knee forces have even greater significance after knee arthroplasty and can directly affect the wear and damage of the artificial materials used in knee replacement components, as well as influence the remodeling of the underlying bone, and can impact the integrity of the interface between the implants and the bone. The complexity of the knee joint makes it difficult for computer models to accurately predict knee forces. Therefore, direct measurements are critical to better understand the progress and modulation of diseases, such as osteoarthritis, as well as to enhance the design, surgical implantation and postoperative care of the reconstructed knee.

In 1998, a massive (tumor replacement) distal femoral prosthesis was instrumented to measure the forces and moments in the femoral shaft. These measured forces were then used to calculate the joint forces at the hinged knee joint $[68,69]$. Anderson and colleagues measured medial compartment pressures intraoperatively using percutaneous pressure sensors inserted during arthroscopy [21]. However, the human knee joint was the last of the major joints to be implanted with permanent sensors (after the spine, hip, and shoulder) $[4,7,70,71]$. This was in part due to the technical challenges of incorporating the sensors and telemetry system within the smaller footprint of a knee arthroplasty tibial tray. The first in vivo knee forces were measured in 2004 using an early generation device that only measured uniaxial forces $[4,70,72]$. From the measured uniaxial forces at four quadrants in the tibial tray, the center of pressure and the mediolateral distribution of forces could also be calculated $[4,72]$. However, this device could not measure anterior shear and axial torque, both of which are important components of force in the knee joint. In 2005, a second-generation device that measured all six components of forces and moments of the tibial tray was implanted $[7,71,73]$. The second-generation sensor design consisted of a redundant array of 12 strain gages that collectively yielded the three components of force and three moments [73]. Independently, the team led by Bergmann subsequently instrumented a tibial tray that 
measured all six components of forces, which increased the total number of patients with implanted sensors in the knee joint to ten [74-77].

Tibial forces were monitored over the first postoperative year: with peak knee forces progressively increasing before eventually reaching an average of $2.8 \mathrm{xBW}$ at the end of the first postoperative year $[4,74]$. Forces through the medial compartment averaged $55 \%$ of total force [78]. During the stance phase of walking, the axial force through the medial compartment averaged $73 \%$ for the first peak and $65 \%$ for the second peak [79]. This mediolateral distribution of forces was correlated with limb alignment with a $1^{\circ}$ varus deviation increasing the medial loading by $5 \%$. A summary of the tibial forces for other activities of daily living are provided in Table 1. These instrumented knee implants have been used to test the efficacy of deliberately altering knee forces, for example, as one potential approach to the prevention and treatment of osteoarthritis.

Osteoarthritis remains intractable with no known disease-modifying therapy. Because of the biomechanical factors contributing to the onset and progression of osteoarthritis, several therapies have targeted reduction in knee forces and in adduction moments. Examples of these approaches include shoe orthotics, braces, walking aids, gait modification, and treadmills. External measurements incorporating motion analysis and ground reaction forces have only provided indirect evidence to support these techniques. Directly measuring the effect of these biomechanical modifications on the magnitude and distribution of tibial forces in vivo is therefore very attractive.

A gait-modification technique that exaggerated the medial thrust at the knee in an attempt to generate a valgus moment during walking was found to reduce medial compartmental loads by 7 to $28 \%$ [80]. Hiking poles were even more effective, reducing medial compartmental force by up to $45 \%$ [80]. The benefit of a cane depended on which side the cane was used: reducing peak abduction moment on the tibial tray by $43 \%$ on the contralateral side, while increasing the abduction moment by $9 \%$ on the ipsilateral side [81].

Lateral wedges in the soles of shoes have been shown to reduce the external adduction moment at the knee in some studies and therefore reduce medial knee loads in an attempt to relieve medial compartmental osteoarthritis. However, not all studies consistently reported successful changes in adduction moment. In an attempt to resolve conflicting reports, the mediolateral distribution of knee forces was directly measured in six subjects with instrumented tibial trays [75]. Wedges alone were found to reduce average medial forces by only 1 to $4 \%$, although one subject benefited from a $15 \%$ medial force reduction. A variable stiffness shoe simulates the effect of a dynamic lateral wedge with the potential for less subjective discomfort than a static wedge. Since the lateral half of the sole is stiffer than the medial half, the medial sole compresses more on weight bearing, producing a similar effect as a lateral wedge. A variable stiffness shoe reduced the peak external adduction moment of the knee in subjects with medial compartmental osteoarthritis [82]. Medial compartment joint contact force was also reduced compared to wearing a shoe without the variable stiffness sole [83].

Valgus knee braces were used in an attempt to relieve medial compartmental forces by reducing the external adduction moment. Direct measurement of medial compartment pressures using arthroscopically inserted temporary percutaneous pressure sensors in 11 subjects could not detect any significant benefit of unloading braces [21]. Knee forces were therefore measured in vivo in instrumented trays for more direct assessment [77]. Both the design of the brace and the degree of valgus adjustment were found to affect medial tibial forces. Using an extreme valgus adjustment of $8^{\circ}$ in one brace design was found to reduce peak medial forces by up to $30 \%$ during walking and stair climbing (although this extreme valgus setting was considered too uncomfortable for prolonged use).

Lower body-positive pressure chambers can reduce net ground reaction forces and can relieve postoperative pain during ambulation. Placing a treadmill inside a pressurized chamber can reduce the effect of gravity on the lower extremities during walking. The patient is positioned with his or her lower body within the chamber. A neoprene seal at the waist maintains the pressure differential between the lower and upper body. A positive pressure (that is, higher pressure within the chamber) lifts the patient and reduces the ground reaction force on the treadmill. Knee forces monitored in vivo were reduced and correlated with the reduction in treadmill reaction forces [84].

In summary, knee forces have been recorded for a variety of activities ranging from postoperative rehabilitation to activities of daily living, recreation, and athletic exercise (Table 1). One benefit of directly measuring the forces includes the assessment of therapeutic approaches to modulate knee forces. The effect of these techniques can be monitored in instrumented implants and the precise effect on knee forces quantified. An additional value of in vivo experimentally measured knee forces is to validate computational models predicting knee forces. In general, measured knee forces were at the lower range of those predicted, and most mathematical predictions overestimated knee forces compared to those measured in vivo (reviewed in $[81,85]$ ). Using experimental data to support development and validation of mathematical models substantially broadens the utility of these 
electronic implants and extends the value far beyond the small sample size. In addition, the supporting data that are collected in parallel, such as MRI and CT scans, video and fluoroscopic motion analysis, electromyography, and external reaction forces, makes it possible to develop subject-specific models that could drive personalized medicine [85]. These datasets are being released annually for a Grand Challenge Competition held at the ASME Summer Bioengineering Conference and are made available to the musculoskeletal modeling community at [86].

The value of the in vivo measurement of forces and strains is high; however, extrapolation to other total knee arthroplasty patients or to other populations, such as normal subjects, has yet to be validated due to the small sample size. Of all the instrumented orthopedic implants covered in this review, an instrumented tibial tray may be feasible for commercial use. Electronic sensors, which can monitor the distribution of tibiofemoral forces intraoperatively, are now available to supplement surgical instrumentation and computer-aided navigation to quantify the soft-tissue balance of the knee (eLIBRA ${ }^{\circ}$, Synvasive Technology, Inc.; and Orthosensor ${ }^{\mathrm{TM}}$ ). An attractive feature of the Orthosensor ${ }^{\mathrm{TM}}$ Knee Trial is the complete encapsulation of sensors, telemetry, and powering system within the trial insert. Combining this with low-cost manufacturing of disposable units increases economic feasibility. This technology can also be used to instrument tibial trays that have the same dimensions, shape, and structural performance as offthe-shelf arthroplasty components. The availability of in vivo force data from large cohorts of patients is a tremendous advantage to the scientific community, the operating surgeon, and the implant manufacturer. Knowledge of forces within one's knee would also be valuable to the patient in identifying activities at risk and beneficial in modifying postoperative behavior.

\section{Conclusions, potential benefits and future directions}

As technological advances reduce the size and invasiveness of sensors and telemetry systems, measurement of forces in individuals with less surgical reconstruction may become feasible, which will permit extrapolation to normal populations with greater validity. In vivo measurements of stresses and strains have potential value at several levels. The most immediate benefit is to the research and scientific communities in their respective fields: testing and validating conventional wisdom regarding the performance of implants within the body and generating fresh insights into the behavior of musculoskeletal tissues in response to injury, repair, and surgery, as well as the biomechanics of the healing process. In vivo force data for hip, spine, shoulder and knee are freely available at [87]; while datasets combining CT scans, video and fluoroscopic motion analysis, electromyography, and external reaction forces are available at the link referenced in the following citation [86].

The next level of benefit is to the designers and manufacturers of the medical devices and implants as they incorporate the newly acquired data into developing the next-generation devices. In vivo data are also being used to develop more clinically relevant laboratory and computer models for preclinical testing of medical devices as a basis for improving international standards of testing of these devices, and informing regulatory agencies (such as the FDA in the USA, or EU directives governing $\mathrm{CE}$ marking) in establishing guidelines with respect to the safety of new medical devices.

A third level of benefit is in providing biofeedback to patients. Direct measurement of implant strain during activity is an unambiguous and quantitative signal. One example is the monitoring of activity that places the implant or surgery at risk for biomechanical failure. This risk of failure was 15 times higher in patients that did not follow recommended postoperative restrictions and when experimentally measured deformation was above the fatigue limit for the implant material [88].

A final benefit, which effectively tightens the design, development, and testing loop, is the analysis of unsupervised data collected under field conditions, which will yield direct assessment of implant efficacy and performance as well as generate early biomarkers of success and failure [89]. These data will greatly enhance evidence-based medicine.

To realize all these benefits, several technical and safety bottlenecks have to be overcome. Sensor and telemetry systems have to be miniaturized to fit within the footprint of standard medical devices without modifications that would jeopardize the performance or reducing the safety of the implants. Another issue is providing long-term power in the form of enhanced and safer battery technology, unobtrusive electromagnetic induction, or alternative approaches such as energy harvesting from applied forces or body temperature. The additional cost of these modifications has to be low enough to make these devices commercially competitive, at least until the value of all the benefits can be established and balanced against cost. Wireless data transmission protocols have to be standardized and approved, and integration with electronic medical records has to be carefully considered. Finally, one has to deal with the massive amounts of data being generated and bandwidth, storage, retrieval, and protection of patient privacy will all be of critical concern.

This article is part of the series on Cutting edge topics and advances in orthopaedic research, edited by Edward Schwarz and

Jay Lieberman. Other articles in this series can be found at http://arthritis-research.com/series/orthopaedics 


\section{Abbreviations}

$C T$, computed tomography; MRI, magnetic resonance imaging; xBW, times body weight.

\section{Competing interests}

The authors declare that they have no competing interests.

\section{Author details}

'Scripps Health, Shiley Center for Orthopaedic Research and Education at Scripps Clinic, 11025 North Torrey Pines Road, Suite 200, La Jolla, CA 92037-1030, USA. ²Department of Mechanical and Aerospace Engineering, 231 MAE-A Building, Box 116250, University of Florida, Gainesville, FL 32611-6520, USA

Published: 31 January 2013

\section{References}

1. Lanyon LE, Hampson WG, Goodship AE, Shah JS: Bone deformation recorded in vivo from strain gauges attached to the human tibial shaft. Acta Orthop Scand 1975, 46:256-268.

2. Burr DB, Milgrom C, Fyhrie D, Forwood M, Nyska M, Finestone A, Hoshaw S, Saiag $E$, Simkin A: In vivo measurement of human tibial strains during vigorous activity. Bone 1996, 18:405-410.

3. Szivek JA, Magee FP: A long-term in vivo bone strain measurement device. J Invest Surg 1989, 2:195-206.

4. D'Lima DD, Patil S, Steklov N, Slamin JE, Colwell CW Jr: The Chitranjan Ranawat Award: in vivo knee forces after total knee arthroplasty. Clin Orthop Relat Res 2005, 440:45-49.

5. Bergmann G, Graichen F, Bender A, Rohlmann A, Halder A, Beier A, Westerhoff $P$ : In vivo gleno-humeral joint loads during forward flexion and abduction. J Biomech 2011, 44:1543-1552.

6. Szivek JA, Bliss CL, Geffre CP, Margolis DS, DeYoung DW, Ruth JT, Schnepp AB, Tellis BC, Vaidyanathan RK: An instrumented scaffold can monitor loading in the knee joint. J Biomed Mater Res B Appl Biomater 2006, 79:218-228.

7. D'Lima DD, Patil S, Steklov N, Chien S, Colwell CW Jr: In vivo knee moments and shear after total knee arthroplasty. J Biomech 2007, 40:S11-S17.

8. Bergmann G, Graichen F, Bender A, Kääb M, Rohlmann A, Westerhoff P: In vivo glenohumeral contact forces--measurements in the first patient 7 months postoperatively. J Biomech 2007, 40:2139-2149.

9. Brown $\mathrm{RH}$, Burstein $\mathrm{AH}$, Frankel $\mathrm{VH}$ : Telemetering in vivo loads from nail plate implants. J Biomech 1982, 15:815-823.

10. Hodge WA, Fijan RS, Carlson KL, Burgess RG, Harris WH, Mann RW: Contact pressures in the human hip joint measured in vivo. Proc Natl Acad Sci U S A 1986, 83:2879-2883.

11. Szivek JA, Roberto RF, Margolis DS: In vivo strain measurements from hardware and lamina during spine fusion. J Biomed Mater Res B Appl Biomater 2005, 75:243-250.

12. Rydell NW: Forces acting on the femoral head-prosthesis. A study on strain gauge supplied prostheses in living persons. Acta Orthop Scand 1966, 37 (Suppl 88):1-132.

13. English T, Kilvington M: In vivo records of hip loads using a femoral implant with telemetric output. J Biomed Eng 1979, 1:111-115.

14. Szivek JA, Margolis DS, Garrison BK, Nelson E, Vaidyanathan RK, DeYoung DW: TGF-beta1-enhanced TCP-coated sensate scaffolds can detect bone bonding. J Biomed Mater Res B Appl Biomater 2005, 73:43-53.

15. Kenwright J, Richardson JB, Cunningham JL, White SH, Goodship AE, Adams MA, Magnussen PA, Newman JH: Axial movement and tibial fractures. A controlled randomised trial of treatment. J Bone Joint Surg Br 1991, 73:654-659.

16. Wade RH, Moorcroft Cl, Thomas PB: Fracture stiffness as a guide to the management of tibial fractures. J Bone Joint Surg Br 2001, 83:533-535.

17. Dwyer JS, Owen PJ, Evans GA, Kuiper JH, Richardson JB: Stiffness measurements to assess healing during leg lengthening. A preliminary report. J Bone Joint Surg Br 1996, 78:286-289.

18. Burny F, Donkerwolcke M, Bourgois R, Domb M, Saric O: Twenty years experience in fracture healing measurements with strain gauges. Orthopedics 1984, 7:1823-1826.

19. Schneider E, Michel MC, Genge M, Zuber K, Ganz R, Perren SM: Loads acting in an intramedullary nail during fracture healing in the human femur. J Biomech 2001, 34:849-857.

20. Hodge WA, Carlson KL, Fijan RS, Burgess RG, Riley PO, Harris WH, Mann RW: Contact pressures from an instrumented hip endoprosthesis. J Bone Joint
Surg Am 1989, 71:1378-1386.

21. Anderson IA, MacDiarmid AA, Lance Harris M, Mark Gillies R, Phelps R, Walsh WR: A novel method for measuring medial compartment pressures within the knee joint in-vivo. J Biomech 2003, 36:1391-1395.

22. Geffre CP, Bliss CL, Szivek JA, Deyoung DW, Ruth JT, Margolis DS: Sensate scaffolds coupled to telemetry can monitor in vivo loading from within a joint over extended periods of time. J Biomed Mater Res B Appl Biomater 2008, 84:263-270.

23. Bliss CL, Szivek JA, Tellis BC, Margolis DS, Schnepp AB, Ruth JT: Sensate scaffolds can reliably detect joint loading. J Biomed Mater Res B Appl Biomater 2007, 81:30-39.

24. Carlson CE, Mann RW, Harris WH: A look at the prosthesis-cartilage interface: design of a hip prosthesis containing pressure transducers. J Biomed Mater Res 1974, 8:261-269.

25. Carlson CE, Mann RW, Harris WH: A radio telemetry device for monitoring cartilage surface pressures in the human hip. IEEE Trans Biomed Eng 1974, 21:257-264.

26. Davy DT, Kotzar GM, Brown RH, Heiple KG, Goldberg VM, Heiple KG Jr, Berilla J, Burstein AH: Telemetric force measurements across the hip after total arthroplasty. J Bone Joint Surg Am 1988, 70-A:45-50.

27. Bergmann G, Graichen F, Rohlmann A: Hip joint loading during walking and running, measured in two patients. J Biomech 1993, 26:969-090.

28. Kotzar GM, Davy DT, Goldberg VM, Heiple KG, Berilla J, Heiple KG Jr, Brown RH, Burstein $\mathrm{AH}$ : Telemeterized in vivo hip joint force data: a report on two patients after total hip surgery. J Orthop Res 1991, 9:621-633.

29. Damm P, Graichen F, Rohlmann A, Bender A, Bergmann G: Total hip joint prosthesis for in vivo measurement of forces and moments. Med Eng Phys 2010, 32:95-100.

30. Bergmann G, Kniggendorf H, Graichen F, Rohlmann A: Influence of shoes and heel strike on the loading of the hip joint. J Biomech 1995, 28:817-827.

31. Bergmann G, Graichen F, Rohlmann A: Hip joint contact forces during stumbling. Langenbecks Arch Surg 2004, 389:53-59.

32. Ledet EH, D'Lima D, Westerhoff P, Szivek JA, Wachs RA, Bergmann G: Implantable sensor technology: from research to clinical practice. J Am Acad Orthop Surg 2012, 20:383-392.

33. Pedersen DR, Brand RA, Davy DT: Pelvic muscle and acetabular contact forces during gait. J Biomech 1997, 30:959-965.

34. Bergmann G, Graichen F, Rohlmann A, Bender A, Heinlein B, Duda GN, Heller MO, Morlock MM: Realistic loads for testing hip implants. Biomed Mater Eng 2010, 20:65-75

35. Heller MO, Bergmann G, Kassi JP, Claes L, Haas NP, Duda GN: Determination of muscle loading at the hip joint for use in pre-clinical testing. J Biomech 2005, 38:1155-1163.

36. Stansfield BW, Nicol AC, Paul JP, Kelly IG, Graichen F, Bergmann G: Direct comparison of calculated hip joint contact forces with those measured using instrumented implants. An evaluation of a three-dimensional mathematical model of the lower limb. J Biomech 2003, 36:929-936.

37. Waugh T: Intravital measurements during instrumental correction of idiopathic scoliosis. Acta Orthop Scand 1966, 93:58-75

38. Nachemson A, Elfstrom G: Intravital wireless telemetry of axial forces in Harrington distraction rods in patients with idiopathic scoliosis. J Bone Joint Surg Am 1971, 53-A:445-465.

39. Elfstrom $G$, Nachemson $A$ : Telemetry recordings of forces in the harrington distraction rod: a method for increasing safety in the operative treatment of scoliosis patients. Clin Orthop Relat Res 1973, 93:158-172.

40. Rohlmann A, Bergmann G, Graichen F: A spinal fixation device for in vivo load measurement. J Biomech 1994, 27:961-967.

41. Rohlmann A, Graichen F, Bender A, Kayser R, Bergmann G: Loads on a telemeterized vertebral body replacement measured in three patients within the first postoperative month. Clin Biomech (Bristol, Avon) 2008, 23:147-158.

42. Rohlmann A, Bergmann G, Graichen F, Weber U: Comparison of loads on internal spinal fixation devices measured in vitro and in vivo. Med Eng Phys 1997, 19:539-546.

43. Nachemson A: The load on lumbar disks in different positions of the body. Clin Orthop Relat Res 1966, 45:107-122.

44. Rohlmannt A, Claes LE, Bergmannt G, Graichen F, Neef P, Wilke HJ: Comparison of intradiscal pressures and spinal fixator loads for different body positions and exercises. Ergonomics 2001, 44:781-794.

45. Sato K, Kikuchi S, Yonezawa T: In vivo intradiscal pressure measurement in healthy individuals and in patients with ongoing back problems. Spine 
(Phila Pa 1976) 1999, 24:2468-2474.

46. Wilke HJ, Neef P, Caimi M, Hoogland T, Claes LE: New in vivo measurements of pressures in the intervertebral disc in daily life. Spine (Phila Pa 1976) 1999, 24:755-762.

47. Ledet EH, Sachs BL, Brunski JB, Gatto CE, Donzelli PS: Real-time in vivo loading in the lumbar spine. Part 1. Interbody implant: load cell design and preliminary results. Spine 2000, 25:2595-2600.

48. Ledet EH, Tymeson MP, DiRisio DJ, Cohen B, UhI RL: Direct real-time measurement of in vivo forces in the lumbar spine. Spine J 2005, 5:85-94.

49. Dreischarf M, Bergmann G, Wilke HJ, Rohlmann A: Different arm positions and the shape of the thoracic spine can explain contradictory results in the literature about spinal loads for sitting and standing. Spine 2010, 35:2015-2021.

50. Rohlmann A, Zander T, Graichen F, Dreischarf M, Bergmann G: Measured loads on a vertebral body replacement during sitting. Spine J 2011, 11:870-875

51. Rohlmann A, Bergmann G, Graichen F, Weber U: Changes in the loads on an internal spinal fixator after iliac-crest autograft. J Bone Joint Surg Br 2000, 82:445-449

52. Rohlmann A, Bauer L, Zander T, Bergmann G, Wilke HJ: Determination of trunk muscle forces for flexion and extension by using a validated finite element model of the lumbar spine and measured in vivo data. J Biomech 2006, 39:981-989

53. Rohlmann A, Zander T, Rao M, Bergmann G: Realistic loading conditions for upper body bending. J Biomech 2009, 42:884-890.

54. Westerhoff P, Graichen F, Bender A, Halder A, Beier A, Rohlmann A, Bergmann $G$ : In vivo measurement of shoulder joint loads during activities of daily living. J Biomech 2009, 42:1840-1849.

55. Amin S, Luepongsak N, McGibbon CA, LaValley MP, Krebs DE, Felson DT: Knee adduction moment and development of chronic knee pain in elders. Arthritis Rheum 2004, 51:371-376.

56. Felson DT, Zhang Y, Hannan MT, Naimark A, Weissman B, Aliabadi P, Levy D: Risk factors for incident radiographic knee osteoarthritis in the elderly: the Framingham Study. Arthritis Rheum 1997, 40:728-733.

57. Roemer FW, Zhang Y, Niu J, Lynch JA, Crema MD, Marra MD, Nevitt MC, Felson DT, Hughes LB, El-Khoury GY, Englund M, Guermazi A; Multicenter Osteoarthritis Study Investigators: Tibiofemoral joint osteoarthritis: risk factors for MR-depicted fast cartilage loss over a 30-month period in the multicenter osteoarthritis study. Radiology 2009, 252:772-780

58. Felson DT, Anderson JJ, Naimark A, Walker AM, Meenan RF: Obesity and knee osteoarthritis. The Framingham Study. Ann Intern Med 1988, 109:18-24.

59. Blagojevic M, Jinks C, Jeffery A, Jordan KP: Risk factors for onset of osteoarthritis of the knee in older adults: a systematic review and metaanalysis. Osteoarthritis Cartilage 2010, 18:24-33.

60. Niu J, Zhang YQ, Torner J, Nevitt M, Lewis CE, Aliabadi P, Sack B, Clancy M, Sharma L, Felson DT: Is obesity a risk factor for progressive radiographic knee osteoarthritis? Arthritis Rheum 2009, 61:329-335.

61. Sharma L, Lou C, Felson DT, Dunlop DD, Kirwan-Mellis G, Hayes KW, Weinrach D, Buchanan TS: Laxity in healthy and osteoarthritic knees. Arthritis Rheum 1999, 42:861-870.

62. Sharma L, Song J, Felson DT, Cahue S, Shamiyeh E, Dunlop DD: The role of knee alignment in disease progression and functional decline in knee osteoarthritis. JAMA 2001, 286:188-195.

63. Tanamas S, Hanna FS, Cicuttini FM, Wluka AE, Berry P, Urquhart DM: Does knee malalignment increase the risk of development and progression of knee osteoarthritis? A systematic review. Arthritis Rheum 2009, 61:459-467.

64. Thorp LE, Sumner DR, Wimmer MA, Block JA: Relationship between pain and medial knee joint loading in mild radiographic knee osteoarthritis. Arthritis Rheum 2007, 57:1254-1260

65. Prodromos CC, Andriacchi TP, Galante JO: A relationship between gait and clinical changes following high tibial osteotomy. J Bone Joint Surg Am 1985, 67:1188-1194.

66. Sharma L, Hurwitz DE, Thonar EJ, Sum JA, Lenz ME, Dunlop DD, Schnitzer TJ, Kirwan-Mellis G, Andriacchi TP: Knee adduction moment, serum hyaluronan level, and disease severity in medial tibiofemoral osteoarthritis. Arthritis Rheum 1998, 41:1233-1240.

67. Baliunas AJ, Hurwitz DE, Ryals AB, Karrar A, Case JP, Block JA, Andriacchi TP. Increased knee joint loads during walking are present in subjects with knee osteoarthritis. Osteoarthritis Cartilage 2002, 10:573-579.

68. Taylor SJ, Walker PS: Forces and moments telemetered from two distal femoral replacements during various activities. J Biomech 2001، 34:839-848.
69. Taylor SJ, Walker PS, Perry JS, Cannon SR, Woledge R: The forces in the distal femur and the knee during walking and other activities measured by telemetry. J Arthroplasty 1998, 13:428-437.

70. D'Lima DD, Patil S, Steklov N, Slamin JE, Colwell CW Jr: Tibial forces measured in vivo after total knee arthroplasty. J Arthroplasty 2006, 21:255-262.

71. D'Lima DD, Steklov N, Patil S, Colwell CW Jr: The Mark Coventry Award: in vivo knee forces during recreation and exercise after knee arthroplasty. Clin Orthop Relat Res 2008, 466:2605-2611

72. D'Lima DD, Townsend CP, Arms SW, Morris BA, Colwell CW Jr: An implantable telemetry device to measure intra-articular tibial forces. J Biomech 2005, 38:299-304.

73. Kirking B, Krevolin J, Townsend C, Colwell CW Jr, D'Lima DD: A multiaxial force-sensing implantable tibial prosthesis. J Biomech 2006, 39:1744-1751.

74. Heinlein B, Kutzner I, Graichen F, Bender A, Rohlmann A, Halder AM, Beier A, Bergmann G: ESB Clinical Biomechanics Award 2008: Complete data of total knee replacement loading for level walking and stair climbing measured in vivo with a follow-up of 6-10 months. Clin Biomech (Bristol, Avon) 2009, 24:315-326.

75. Kutzner I, Damm P, Heinlein B, Dymke J, Graichen F, Bergmann G: The effect of laterally wedged shoes on the loading of the medial knee compartment-in vivo measurements with instrumented knee implants. J Orthop Res 2011, 29:1910-1915.

76. Kutzner I, Heinlein B, Graichen F, Bender A, Rohlmann A, Halder A, Beier A, Bergmann G: Loading of the knee joint during activities of daily living measured in vivo in five subjects. J Biomech 2010,43:2164-2173.

77. Kutzner I, Küther S, Heinlein B, Dymke J, Bender A, Halder AM, Bergmann G The effect of valgus braces on medial compartment load of the knee joint - in vivo load measurements in three subjects. J Biomech 2011, 44:1354-1360.

78. Zhao D, Banks SA, D'Lima DD, Colwell CW Jr, Fregly BJ: In vivo medial and lateral tibial loads during dynamic and high flexion activities. J Orthop Res 2007, 25:593-602.

79. Halder A, Kutzner I, Graichen F, Heinlein B, Beier A, Bergmann G: Influence of limb alignment on mediolateral loading in total knee replacement: in vivo measurements in five patients. J Bone Joint Surg Am 2012, 94:1023-1029.

80. Fregly BJ, D'Lima DD, Colwell Jr CW: Effective gait patterns for offloading the medial compartment of the knee. J Orthop Res 2009, 27:1016-1021.

81. D'Lima DD, Fregly BJ, Patil S, Steklov N, Colwell CW Jr: Knee joint forces: Prediction, measurement, and significance. Proc Inst Mech Eng H 2012, 226:95-102.

82. Erhart JC, Mündermann A, Elspas B, Giori NJ, Andriacchi TP: A variablestiffness shoe lowers the knee adduction moment in subjects with symptoms of medial compartment knee osteoarthritis. J Biomech 2008, 41:2720-2725

83. Erhart JC, Dyrby CO, D'Lima DD, Colwell CW, Andriacchi TP: Changes in in vivo knee loading with a variable-stiffness intervention shoe correlate with changes in the knee adduction moment. J Orthop Res 2010, 28:1548-1553.

84. Macias BR, D'Lima DD, Cutuk A, Patil S, Steklov N, Neuschwander TB, Meuche $\mathrm{S}$, Colwell CW, Hargens AR: Leg intramuscular pressures and in vivo knee forces during lower body positive and negative pressure treadmill exercise. J App/ Physiol 2011, 113:31-38

85. Fregly BJ, Besier TF, Lloyd DG, Delp SL, Banks SA, Pandy MG, D'Lima DD: Grand challenge competition to predict in vivo knee loads. J Orthop Res 2012, 30:503-513.

86. Grand Challenge Competition to Predict In Vivo Knee Loads [https://simtk.org/home/kneeloads]

87. OrthoLoad [http://www.orthoload.com]

88. Burny F, Donkerwolcke M, Moulart F, Bourgois R, Puers R, Van Schuylenbergh K, Barbosa M, Paiva O, Rodes F, Bégueret JB, Lawes P: Concept, design and fabrication of smart orthopaedic implants. Med Eng Phys 2000, 22:469-479.

89. D'Lima DD, Patil S, Steklov N Colwell CW Jr: The 2011 ABJS Nicolas Andry Award: 'Lab'-in-a-knee: in vivo knee forces, kinematics, and contact analysis. Clin Orthop Relat Res 2011, 469:2953-2970.

doi:10.1186/ar4138

Cite this article as: D'Lima DD, et al.: Implantable sensor technology: measuring bone and joint biomechanics of daily life in vivo. Arthritis Research \& Therapy 2013, 15:203. 